\title{
Mortality and productivity of eelgrass Zostera marina under conditions of experimental burial with two sediment types
}

\author{
Katherine E. Mills ${ }^{1, *}$, Mark S. Fonseca ${ }^{2}$ \\ ${ }^{1}$ Department of Natural Resources, Cornell University, Ithaca, New York 14853, USA \\ ${ }^{2}$ NOAA, National Ocean Service, Center for Coastal Fisheries and Habitat Research, 101 Pivers Island Road, Beaufort, \\ North Carolina 28516, USA
}

\begin{abstract}
Mortality and productivity of Zostera marina L. were assessed to examine the effects of experimental burial using 2 types of sediment: (1) sand (6 and $0.2 \%$ silt-clay and organic matter content, respectively); and (2) silt (27 and 3.3\% silt-clay and organic matter content, respectively). $Z$. marina was buried to $0,25,50,75$ and $100 \%$ of its average aboveground height $(16 \mathrm{~cm})$ in an existing eelgrass bed using 2 types of sediment characterized as either silty or sandy. Increasing percentages of plant burial significantly increased mortality and decreased productivity. Survival and productivity of eelgrass were substantially reduced when only $25 \%$ of the plant height was buried. Plants buried $75 \%$ or more of their height were characterized by survival and productivity measures of 0 . No statistically significant differences in plant mortality or productivity were found between the 2 sediment types in this experiment. Changes in morphology of the plants were detected in measures of leaf length and surface area in a short duration (12 d) trial of the experiment, apparently in response to senescence, but etiolation was not observed. Results of this experiment indicate $Z$. marina can only tolerate rapid sedimentation events that cover less than half of its photosynthetic surfaces. Furthermore, the lowest levels of burial treatments (25\% of plant height) resulted in mortality greater than $50 \%$, indicating that even this small level of rapid sedimentation is significantly detrimental to $Z$. marina.
\end{abstract}

KEY WORDS: Seagrass $\cdot$ Zostera marina $\cdot$ Mortality $\cdot$ Productivity $\cdot$ Burial $\cdot$ Deposition $\cdot$ Sediment type

Resale or republication not permitted without written consent of the publisher

\section{INTRODUCTION}

An important function of seagrasses is their ability to stabilize sediments of shallow marine areas (for a review see Fonseca 1996). Natural events such as storms can distribute sediment over plant surfaces. However, seagrass communities typically establish a long-term equilibrium that accommodates such events (Fonseca et al. 1983, Fonseca \& Bell 1998). In addition, anthropogenic perturbations can increase the sediment load entering seagrass beds. Increased sediment loads in rivers due to upland runoff, trapping of material by beach stabilization projects, and dredging and/or dumping of dredged materials offer examples of anthropogenic activities that may disrupt the equi- librium of the system and impair the condition of seagrass plants (McRoy \& Helfferich 1980, Shepherd et al. 1989, Vermaat et al. 1996, Duarte et al. 1997, Terrados et al. 1998). In addition, vessel groundings (authors' pers. obs.) and the activities of burrowing animals (Suchanek 1983, Ziebis et al. 1996, authors' pers. obs.) often result in substantial displacement of sediment over adjacent seagrass areas.

Burial of seagrass decreases the available photosynthetic area of the plant and increases the respiratory demand of the buried portion. In addition, highly anoxic conditions are likely to occur at some depth below the sediment surface in this area (Kenworthy et al. 1982). Because rapid burial (i.e. faster than a given species can alter its morphology to respond to changes 
in sediment level) raises the sediment surface, the depth of sediment anoxia almost certainly rises upwards toward the photosynthetic portions of the seagrass. These conditions may result in sulfide intrusion of the root system and other newly buried tissues from the surrounding sediments (Goodman et al. 1995, Vermaat et al. 1996). This situation may inhibit the plants' recovery from the burial event and create conditions under which the plants experience elevated physiological stress (Goodman et al. 1995), which if prolonged, could lead to death (McRoy \& Helfferich 1980). However, due to different resource allocation strategies and life history characteristics, seagrass species may vary in their tolerance of sedimentation events, and some species such as Amphibolis griffithii (authors' pers. obs.) may be specially adapted to fluctuating sediment levels (Clarke \& Kirkman 1989, Preen et al. 1995, Duarte et al. 1997, Terrados et al. 1998).

However, to our knowledge, there have been no quantitative examinations of the tolerance of the North American seagrasses to burial events. Therefore, to address this issue, we conducted a burial experiment on one of the dominant North American species, eelgrass Zostera marina L., in the North River estuary near Beaufort, North Carolina. In this experiment, we attempted to identify a threshold at which burial increased the likelihood of mortality or decreased productivity of $Z$. marina. While many scenarios may be envisioned that deposit sediment onto seagrasses, ranging from gradual (days to weeks) to rapid (hours to days), we chose to rapidly bury upright plants at a range of depths in an attempt to isolate the immediate tolerance of this species to different levels of burial.

Our study addressed changes in mortality and productivity of Zostera marina caused by its burial to increasing heights, thereby decreasing available photosynthetic surface area. We hypothesized that productivity would decline with an increasing percentage of plant height buried due to a proportionate reduction in the exposed leaf area able to photosynthesize. Beyond some level, burial was expected to prove fatal to the plants. Organic content of the sediment, which is strongly correlated with particle size in our systems, contributes to a higher sulfide content which may further stress the plants (Kenworthy et al. 1982, Carlson et al. 1994, Goodman et al. 1995). Therefore, to test the effect of varying levels of sediment composition on plant mortality and productivity, we buried plants in both silt and sand sediment types, where silty sediments had naturally higher organic content. We expected lower productivity and higher mortality for plants buried in silt sediment than those buried in sand. Finally, we anticipated the possibility of morphological changes in the plants themselves caused either by etiolation (Marbà \& Duarte 1994) or deterioration as a response to burial. We hypothesized that should plants survive, they may show longer leaf and sheath lengths to a certain depth of burial, but that surface area would remain constant since the plants would be under poor conditions for increasing their total biomass.

\section{MATERIALS AND METHODS}

Experimental design. Three species of seagrass are found in estuarine areas near Beaufort, NC, during various times of the year. Zostera marina is near the southern limit of its Atlantic range in NC. It grows mainly between fall (October) and mid-summer (July) with its peak biomass in early June (Kenworthy et al. 1982, Thayer et al. 1984). Its abundance rapidly declines with increasing water temperatures in August and September. During the time of this study, $Z$. marina was the only seagrass species present at the study site. Halodule wrightii and Ruppia maritima begin growing in May, peak in biomass during late summer and decline in October (Thayer et al. 1984).

A $5 \times 12 \mathrm{~m}$ portion of an existing, quiescent eelgrass bed was chosen in the North River near Beaufort, NC $\left(35^{\circ} 42^{\prime} \mathrm{N}, 76^{\circ} 36^{\prime} \mathrm{W}\right.$; reported as site 'ST1' in previous studies, Murphey \& Fonseca 1995, Fonseca \& Bell 1998), within an area of unbroken eelgrass coverage at the $50 \mathrm{~m}$ scale. The site receives semidiurnal tides with an average range of approximately 0.6 to $0.8 \mathrm{~m}$. Water temperature varied from 5.5 to $18^{\circ} \mathrm{C}$ and salinity measured 30 to 35 ppt during the course of the experiment.

The area was divided into 3 blocks, each oriented in a cross-channel direction at a constant depth. Twelve treatments were assigned to each of the 3 blocks in a randomized complete block design. Treatment positions were located $1 \mathrm{~m}$ apart within a block, with an additional space of $1 \mathrm{~m}$ between blocks. Two sediment types, sand and silt, were obtained from areas near the site. Sandy sediment consisted of $2.6 \%$ gravel, $91.66 \%$ sand, $5.9 \%$ silt/clay and $0.24 \%$ organic matter (OM; by combustion at $500^{\circ} \mathrm{C}$ for $4 \mathrm{~h}$ ). The silt sediment was composed of $0 \%$ gravel, $73.3 \%$ sand, $26.7 \%$ silt/clay and $3.31 \%$ OM.

An arbitrary sample of plants in the study area indicated that the average height (sheath plus blades) of Zostera marina at the time of this study was approximately $16 \mathrm{~cm}$. Five burial treatments using each sediment type were established based on this average overall height. Plants were buried to $0 \%(0 \mathrm{~cm}), 25 \%$ $(4 \mathrm{~cm}), 50 \%(8 \mathrm{~cm}), 75 \%(12 \mathrm{~cm})$ or $100 \%(16 \mathrm{~cm})$ of the average height. Burial treatments were contained within $20 \mathrm{~cm}$ tall by $15.2 \mathrm{~cm}$ in diameter polyvinylchloride (PVC) cylinders (Fig. 1). Cylinders were placed at a depth of $\sim 4 \mathrm{~cm}$ into the substrate, approximately to 
the depth of the plant rhizomes. Care was taken not to sever the rhizomes; however, we cannot ensure that the rhizomes were not pushed slightly deeper into the sediment in this process. Cylinders stood aboveground to a height of $16 \mathrm{~cm}$ and this portion remained fully submersed at low tide. Cylinders without sediment ( $0 \%$ fill) served as the sediment controls for the experiment and were arbitrarily assigned to either the sand or the silt treatment group. Cylinder controls (undisturbed areas of the seagrass bed) were also established within the block as a treatment to assess whether the cylinders themselves had any effect on the response of the seagrass.

One replicate of each burial treatment and 2 replicates of the cylinder control were assigned within each block. Three plants in each of the 36 total experimental units were uniquely tagged with numbered strips of aluminum duct tape, and plants were marked using the syringe hole punch technique described by Dennison (1990), as modified from Zieman's staple method (Zieman 1974). As cylinders were filled with sediment, care was taken to ensure that blades were not broken and that plants remained upright within the sediment matrix.

This experiment was conducted twice due to a failure of the sheath marking technique during the first trial (Block 1: February 15 to March 10, 1995; Blocks 2 and 3: February 24 to March 20, 1995). A 29 gauge needle was used to mark plants in the first trial, but these small holes healed beyond recognition during the course of the study. A larger, 20-gauge, needle was

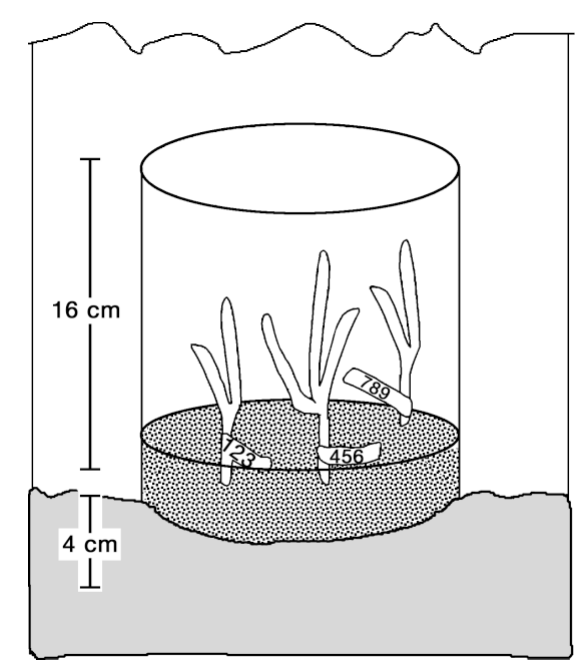

Fig. 1. Zostera marina. Cutaway view of Zostera plants in PVC cylinder filled with small amount of sediment as represented by the light dot-fill near the bottom. Three plants (out of an average of 14 plants per cyclinder) were tagged and marked with a syringe hole through their sheaths in each treatment. Cylinders were placed $4 \mathrm{~cm}$ into the sediment and stood $16 \mathrm{~cm}$ aboveground used for the second trial (March 31 to April 13, 1995). Although productivity could not be assessed during the first trial (24 to $28 \mathrm{~d}$ ), mortality calculations were successfully obtained. The second, shorter trial (12 d) was used to determine productivity differences among treatments. The shorter period of the second trial was necessary because it was later in the year and productivity was expected to be higher. During the second trial, $100 \%$ burial treatments of both sediment types were eliminated because all plants subjected to this treatment died during the first trial and decomposed to the point where they were barely identifiable as to their parent source.

Seagrass analysis. Mortality: Mortality was determined for the first ( 24 to $28 \mathrm{~d}$ ) trial of this experiment. At the time of harvest, plants were considered to be dead if they were completely black, disintegrating and/or had non-rigid rhizomes. Some plants showed signs of stress, such as wilted leaves and black spots. However, these plants were characterized as living, particularly if the rhizome was still rigid, crisply snapping when broken. Plants were not included in this analysis if their labels were not found at harvest. The probability of mortality was calculated for each treatment based on the total number of plants recovered at the end of the experiment. Differences in mortality with burial depth and sediment type were determined using a logistic regression conducted with the logistic procedure (SAS 1986). Cylinder control treatments were included in this analysis as part of the $0 \%$ burial category.

Productivity: Productivity analyses were conducted for only the second (12 d) trial of this experiment. The distance of new leaf growth for marked leaves, sheath length, leaf length and dry weight were measured for each plant harvested. In addition to length measurements, the width of the second youngest leaf was recorded to enable an approximate calculation of total surface area of each plant. Dry weight was determined after drying the plants to a constant weight (approximately $24 \mathrm{~h}$ ) in an oven at $70^{\circ} \mathrm{C}$.

Productivity was measured by developing a regression equation to relate biomass of new leaves and their surface area. Ten samples of leaf portions of varying but known surface areas were randomly selected from plants in this study. Sections were cut and dried to a constant weight to determine biomass. New leaf growth and plant width measured for all plants in this study were used in this equation to estimate the change in surface area during the course of the experiment. This surface area change was then used in the regression equation to determine the $g$ of dry weight produced.

Productivity was calculated for plants that lived and were recovered at the end of the second trial. The effect of the experimental treatments on productivity 
was analyzed with a 2-way ANOVA for a mixed design with 1 random factor (block) and 1 fixed factor (treatment). Grams dry weight (g dry wt) were square-roottransformed to meet the assumptions of least-squares analysis. Statistical analyses were conducted using the mixed procedure (SAS 1986). Linear contrasts were conducted to assess specific effects of interest.

Morphological changes: For the $12 \mathrm{~d}$ experiment, morphological features of plants were compared at the beginning $\left(t_{0}\right)$ and end $\left(t_{1}\right)$ of the experiment. Only plants that survived and were recovered at the end of the $12 \mathrm{~d}$ experiment were included in this analysis, since morphological features could not be measured for dead or decaying plants. Two plants within each $1 \mathrm{~m}^{2}$ treatment were randomly taken at the beginning of the experiment, and sheath and leaf length (sum of the 3 oldest leaves) of each plant were determined in the laboratory. The same measurements as well as plant width were taken for plants from the experimental treatment at the end of the $12 \mathrm{~d}$ experiment. Surface area was calculated for plants at $t_{0}$ and $t_{1}$. The initial surface area $\left(t_{0}\right)$ was computed using the mean width of all plants in the experiment taken at $t_{1}$. Leaf length, sheath length and surface area were compared at $t_{0}$ versus $t_{1}$ using a 1-way ANOVA for each factor conducted with the general linear model procedure (SAS 1986). For this analysis, leaf length and surface area were calculated based on the oldest 3 leaves of the plant since only these leaves were measured on the $t_{0}$ plants.

\section{RESULTS}

\section{Mortality}

Data from the first trial of the experiment were used to determine the probability and likelihood of mortality for Zostera marina under varying levels of burial in the 2 sediment treatments. Ninety-two plants of the 108 originally marked were included in this analysis. The remaining plants could not be found and were therefore left out of the analysis. Of the 92 recovered plants, 58 died during the course of this trial and 34 survived.

Fig. 2 shows the probability of mortality for plants buried to varying levels in 2 sediment types. At a burial depth as low as $25 \%$ of the average aboveground plant height $(4 \mathrm{~cm})$, the probability of mortality exceeded $50 \%$ in both sediment types. The probability of mortality increased rapidly when burial was $50 \%$ of plant height $(8 \mathrm{~cm})$. At this depth, all of the plants in silt sediment were recovered and found to be dead. However, at $50 \%$ burial in sand, only 5 of the 9 plants in the treatment were recovered, and 3 were found to be alive (Table 1). Thus, the probabil-

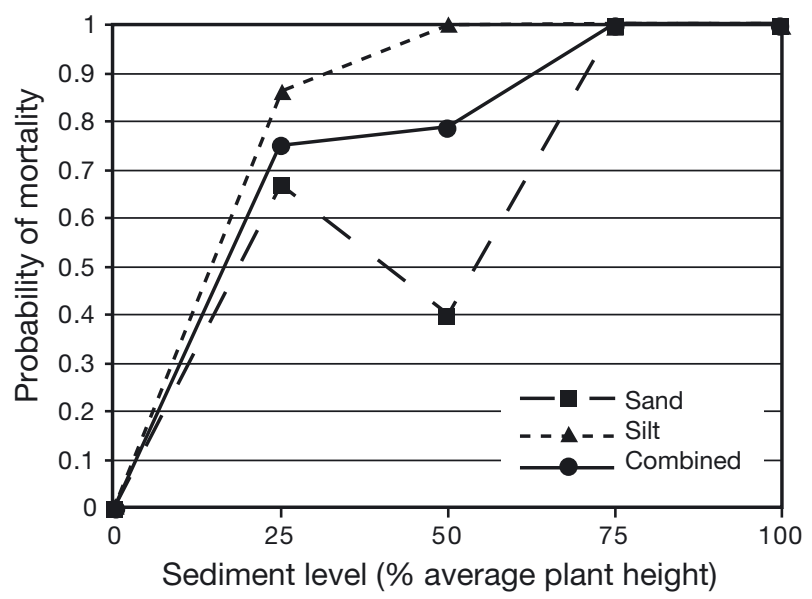

Fig. 2. Zostera marina. Probability of mortality of Zostera plants buried to specified percent of the average plant height in silt and sand sediments. Mortality probabilities are shown for the individual sediment types. In addition, a weighted average based on the number of plants recovered is shown for the combined mortality probability across sediment types at each level of burial

ity of mortality dropped below $50 \%$ for the sand treatment. Although we cannot know for certain, it is possible that some of the 4 plants that were not recovered may have been dead, and the low mortality rate shown in this treatment may simply be an artifact of the lower recovery of plants. Nonetheless, mortality probability, weighted for the number of plants recovered in each treatment and combined across sediment types, shows a clear and sharp increase with burial depth. Combined mortality probabilities of at least $75 \%$ were shown for burial at 25 and $50 \%$ of plant height, and the probability of mortality reached $100 \%$ for burial at and above $75 \%$ of the plant height.

Table 1. Zostera marina. Number of plants in each treatment that were dead, alive or not recovered at the end of the $24 \mathrm{~d}$ experiment

\begin{tabular}{|lccc|}
\hline Treatment & $\begin{array}{c}\text { Number } \\
\text { dead }\end{array}$ & $\begin{array}{c}\text { Number } \\
\text { alive }\end{array}$ & $\begin{array}{c}\text { Not } \\
\text { recovered }\end{array}$ \\
\hline Cylinder control & 0 & 9 & 9 \\
$0 \%$ sand & 0 & 8 & 1 \\
$0 \%$ silt & 0 & 9 & 0 \\
$25 \%$ sand & 6 & 3 & 0 \\
$25 \%$ silt & 6 & 1 & 2 \\
$50 \%$ sand & 2 & 3 & 4 \\
$50 \%$ silt & 9 & 0 & 0 \\
$75 \%$ sand & 8 & 0 & 1 \\
$75 \%$ silt & 9 & 0 & 0 \\
$100 \%$ sand & 9 & 0 & 0 \\
$100 \%$ silt & 9 & 0 & 0 \\
\hline
\end{tabular}


Table 2. Zostera marina. Significance and effects on model fit of sediment depth and type in binary logistic regression model of $Z$. marina mortality, RLL. residual log likelihood

\begin{tabular}{|lrrrrrr|}
\hline & \multicolumn{3}{c}{ Significance of variable } & \multicolumn{3}{c|}{ Fit of model } \\
& $\begin{array}{l}\text { Chi-square } \\
\text { (Wald) }\end{array}$ & $\mathrm{p}$ & Odds ratio & $\begin{array}{c}\text { Chi-square } \\
(-2 \mathrm{RLL})\end{array}$ & $\mathrm{df}$ & $\mathrm{p}$ \\
\hline Sediment depth & 20.2415 & $<0.0001$ & 1.111 & 77.3552 & 1 & $<0.0001$ \\
Sediment type & 1.5598 & 0.2117 & 1.848 & 1.5816 & 1 & 0.2085 \\
\hline
\end{tabular}

(Fig. 3). This equation was used to calculate primary production of the seagrass plants in terms of $g$ dry weight during this experiment.

In this study, burial in either sediment type reduced productivity of Zostera marina, and increasing depths of burial resulted

The likelihood of plant mortality was modeled by the logistic regression equation:

$$
\ln \left(\frac{\mathrm{p}_{\mathrm{m}}}{1-\mathrm{p}_{\mathrm{m}}}\right)=-2.5891+(0.1048 \times \text { sediment depth })
$$

The model achieved a high goodness of fit ( $p<0.0001$ ) and analysis showed a significant effect of increased sediment depth on the likelihood of plant mortality $(\mathrm{p}<0.0001)$ (Table 2). As shown in Table 2, for each incremental increase in burial level, the average odds of plant mortality increased by 1.111. As indicated in Fig. 2, the probability of mortality for plants buried in silt (overall $\mathrm{p}_{\mathrm{m}}=0.767$ ) was slightly higher than for plants in sand (overall $\mathrm{p}_{\mathrm{m}}=0.641$ ). However, the logistic regression analysis indicated that sediment type did not make a statistically significant contribution to the likelihood of plant mortality, nor did inclusion of sediment type as a covariate significantly improve model fit.

\section{Productivity}

The equation, dry wt $=\left[\left(2.27 \times 10^{-3}\right) \times\left(\mathrm{cm}^{2}\right.\right.$ surface area $)]+\left(-6.921 \times 10^{-5}\right)$, was found to relate biomass and surface area of plants in this experiment $(\mathrm{r}=0.67)$

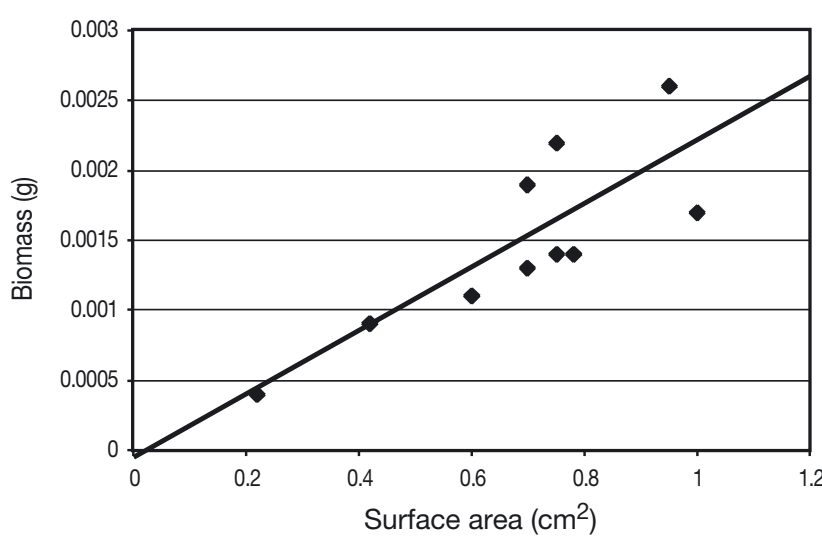

Fig. 3. Zostera marina. Regression of surface area $\left(\mathrm{cm}^{2}\right)$ to biomass (g). ( ) show actual measurements of 10 plants. Solid line represents the best-fit regression equation to predict biomass based on surface area $(r=0.67)$ in related reductions in plant productivity as well (Table 3). Measures of productivity as g dry weight for each surviving treatment are shown in Fig. 4. Some plants were dead at harvest (e.g. $75 \%$ burial treatments), and we were unable to obtain leaf measurements on other plants due to problems such as torn leaves. All plants in each replicate of the $0 \%$ silt, $75 \%$ sand and $75 \%$ silt (treatments) were either dead or not measurable. We cannot explain the death of all plants in the $0 \%$ silt treatment, particularly since they survived in the previous mortality experiment. However,

Table 3. Zostera marina. Mean and SD for productivity (g dry wt) of $Z$. marina buried to different proportions of total plant height in silty and sandy sediment

\begin{tabular}{|llcc|}
\hline \multicolumn{2}{l}{$\begin{array}{l}\text { Sediment type } \\
\text { or level }\end{array}$} & $\begin{array}{c}\text { Mean dry wt } \\
(\mathrm{g})\end{array}$ & $\mathrm{SD}$ \\
\hline Type & Control & 0.0126 & 0.0047 \\
& Sand & 0.0105 & 0.0059 \\
& Silt & 0.0070 & 0.0038 \\
Level & Control & 0.0124 & 0.0054 \\
& $0 \%$ & 0.0133 & 0.0017 \\
& $25 \%$ & 0.0113 & 0.0048 \\
& $50 \%$ & 0.0053 & 0.0038 \\
& $75 \%$ & 0.0000 & 0.0000 \\
\hline
\end{tabular}

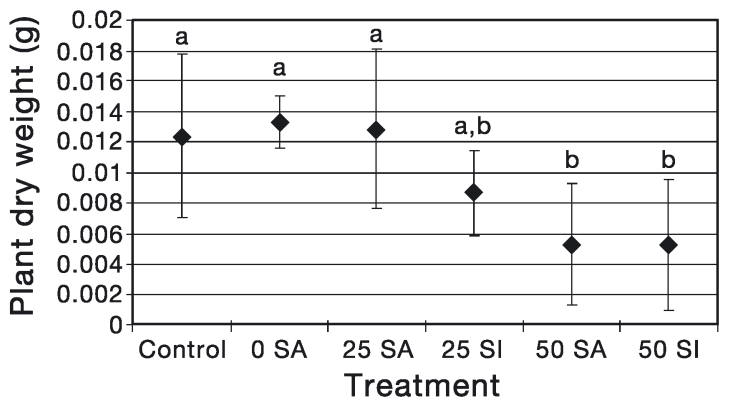

Fig. 4. Zostera marina. Productivity (g dry wt) for each level and type (SA: sand; SI: silt) of burial treatment. Graph shows mean ( $g$ dry wt) and 1 SD from the mean for each treatment in which plants survived and were recovered. Letters associated with each treatment indicate significant differences between the means for each treatment as shown by Duncan's multiple range test (SAS 1986) 
these plants were excluded from statistical analyses, which makes our conclusions more conservative. Patterns in mean productivity of other treatments show a decrease in productivity with burial greater than $25 \%$ of plant height. At $75 \%$ burial, plants died even within the $12 \mathrm{~d}$ duration of this second trial.

Statistical analyses of productivity were conducted for only the plants that survived and were recovered at the end of this experiment. The effects of block and block by treatment were not significant; therefore, the reduced model that included only treatment effects was used for further data interpretations and reporting. Productivity varied significantly between treatments in this experiment $(F=3.21, \mathrm{df}=5, \mathrm{p}=0.020)$. A significant difference in productivity was evident for differences in the level of burial $(t=2.97, \mathrm{p}=0.0060)$. However, no significant differences were attributable to sediment types $(t=-0.58, \mathrm{p}=0.5632)$. Thus, there was no evidence that particle size or organic content of the sediment affected plant productivity. This indicates that the depth of burial is driving the significant difference noted in productivity between treatments. Burial at depths greater than $25 \%$ of the plant height caused productivity to decrease regardless of sediment type.

\section{Morphology}

Plants subjected to burial treatments showed morphological differences from naturally occurring plants in the same area during the course of this study. Due to the observation of etiolation as a response to burial in other seagrass species (Marbà \& Duarte 1994), we anticipated that total surface area of plants subjected to burial would remain constant, while leaf and sheath length may increase (i.e. plants may grow longer while sacrificing width in an effort to increase the portion of leaves above the buried area). However, our results do not support this hypothetical response to burial.

We compared total leaf length, sheath length and surface area of a random sample of plants at the begin-

Table 4. Zostera marina. Descriptive statistics for morphological features measured on plants near the experimental area prior to initiation of the study and on plants after burial as part of the $12 \mathrm{~d}$ experiment. Lengths are given in $\mathrm{cm}$ and areas in $\mathrm{cm}^{2}$

\begin{tabular}{|lclrr|}
\hline Time & $\mathrm{n}$ & Feature & Mean & $\mathrm{SD}$ \\
\hline 0 & \multirow{2}{*}{59} & Leaf length & 37.69 & 8.77 \\
& & Sheath length & 4.10 & 1.00 \\
& & Surface area & 9.39 & 2.18 \\
\multirow{3}{*}{1} & \multirow{2}{*}{38} & Leaf length & 29.38 & 8.67 \\
& & Sheath length & 4.38 & 1.07 \\
& & Surface area & 7.61 & 3.03 \\
\hline
\end{tabular}

Table 5. Zostera marina. One-way ANOVA of the morphological parameters measured on $Z$. marina plants in the study area prior to initiation of the study and following burial for $12 \mathrm{~d}$

\begin{tabular}{|lcrr|}
\hline Variable & $\mathrm{R}^{2}$ & F-ratio & \multicolumn{1}{c|}{$\mathrm{p}$} \\
\hline Leaf length & 0.180502 & 20.92 & $<0.0001$ \\
Sheath length $(\mathrm{ln})$ & 0.017492 & 1.69 & 0.1966 \\
Surface area & 0.106672 & 11.34 & 0.0011 \\
\hline
\end{tabular}

ning and buried plants at the end of the $12 \mathrm{~d}$ experiment (Table 4). Sheath length did not show a significant difference over that time. However, leaf length and surface area were substantially lower in plants that endured the burial treatments (Table 5). This provides further evidence that burial may inhibit plant growth even over a short duration. The fact that leaf length decreased suggests that, in this setting, elongation may not provide a compensatory response to burial. However, it is important to note that the $\mathrm{r}^{2}$ values of the fit of the least-squares model was low for all of these tests. Thus, further studies through longerduration experiments may be necessary to fully understand morphological responses of Zostera marina that survived partial burial.

\section{DISCUSSION}

The results of this study demonstrate the increased likelihood of mortality and decreased productivity of Zostera marina under burial conditions. Effects on plant mortality are associated with the depth of burial, but are not strongly influenced by the type of sediment in which plants are buried. Burial to depths as low as $25 \%$ of the aboveground plant height substantially increased mortality, with burial at this level causing the death of $>75 \%$ of the plants. It appears that the threshold level of burial tolerance for $Z$. marina is extremely low. The mortality probability reached $100 \%$ between burial depths of 50 to $75 \%$ of plant height, depending on the type of sediment in which plants were buried.

Trends in productivity results were less decisive than those for mortality. Ignoring the effect of sediment type, all treatments with burial of $50 \%$ plant height or greater had significantly lower productivity than the controls. At $75 \%$ burial, plants died and productivity was 0. Growth of other seagrass species can be enhanced under low levels of sedimentation or burial (Gallegos et al. 1993, Marbà \& Duarte 1994), and some species such as Amphibolis griffithii may be specifically adapted to periodic burial (authors' pers. obs.). However, in our study, burial even at low levels did not increase growth of Zostera marina. The plants did 
show a slightly higher productivity in the $25 \%$ sand treatment, but this did not differ significantly from the controls. Conversely, the $25 \%$ silt treatment reduced plant productivity.

For both mortality and productivity, sediment depth contributed significantly to the observed effects, whereas sediment type did not contribute significantly to the response. We posited that survival and growth would be higher in sand than in silt. The silt sediment with its higher organic matter content has been associated with less oxygen and stronger reducing conditions in the sediment (Kenworthy et al. 1982). Without sufficient oxygen supply for the plants, sulfide intrusion of their roots may occur (Carlson et al. 1994, Goodman et al. 1995). From our short study, however, it appears that the physical and chemical properties of sediment as applied via our experimental manipulation do not mediate the overall effect of burial on plant mortality and productivity. Burial contributed to reduced productivity and increased mortality of Zostera marina, and this main effect was not significantly influenced by different sediment types used in our study. Effects due to sediment type may be masked by the relatively short duration of our experiments and may have become evident if studies were continued for a longer time. The first-order (main-effect) response clearly relates to simple extent of burial; however, concentrations of organic matter higher than those tested here or longer exposure to organic sediments at reduced levels of burial may contribute further to the demise of $Z$. marina plants.

Changes in leaf length and surface area of the plants were noted during the course of this study. We anticipated that plants may show evidence of etiolation as observed in previous studies with other species (Marbà \& Duarte 1994). Thus, we expected an increase in leaf length as plants respond with growth that moves photosynthetic surfaces above the burial interface. Through etiolation, it was expected that width would be sacrificed to enhance length and that total surface area would remain constant. Instead, plants subjected to burial treatments were significantly shorter in length and smaller in surface area than unburied plants, which was consistent with our observations of their senescence. This may indicate that even low levels of sedimentation may inhibit the plants' ability to respond quickly in a compensatory manner. However, the short duration of this study may not have provided sufficient time for plants to redirect their growth energy in response to sedimentation. A longer study under low conditions of burial may be necessary to fully understand the morphological changes of plants as non-lethal responses to sedimentation.

One may anticipate several detrimental effects of acute sedimentation in seagrass beds, such as com- plete burial and breakage of plants. However, this study attempted to emulate sedimentation events that allow plants to remain standing in the water column such as might be expected when high loads of suspended sediment settle out of the water column or sediments saltate into a bed with storm events. Our results indicate that even more gradual sedimentation events, occurring over several days, that do not otherwise damage the plant structure can pose substantial threats to the survival and growth of seagrasses. Regardless of the form of sedimentation, Zostera marina appears to be sensitive to burial, compared with other species in the Mediterranean (Posidonia oceanica) and Australia (Amphibolis griffithii) (Vermaat et al. 1996, authors' pers. obs.). Engulfing even a small portion of $Z$. marina's photosynthetic surface substantially increases mortality and decreases productivity. Activities in and adjacent to $Z$. marina beds and, potentially, seagrass species with similar morphology and growth strategies, should be carefully planned to minimize sediment disturbance, suspension of particles that may settle out on the plants and insinuation of bulk sediment into the habitat.

Acknowledgements. We would like to thank Dr. Peter Howd, Paula Whitfield, Piera Giroux and Jennison Kipp for assistance with establishing field experiments. Dr. Peter Howd provided laboratory space and critical assessments of the work. In addition, we acknowledge and thank 3 anonymous reviewers whose comments improved the manuscript. This work was supported by funding from the NOAA, National Ocean Service, Center for Coastal Fisheries and Habitat Research, and the Duke University Marine Laboratory.

\section{LITERATURE CITED}

Carlson PR, Yarbro LA, Barber TR (1994) Relationship of sediment sulfide to mortality of Thalassia testudinum in Florida Bay. Bull Mar Sci 54:733-746

Clarke SM, Kirkman H (1989) Seagrass dynamics. In: Larkum AWD, McComb AJ, Shepherd SA (eds) Biology of seagrasses. Elsevier, Amsterdam, p 304-345

Dennison WC (1990) Leaf production. In: Phillips RC, McRoy CP (eds) Seagrass research methods. UNESCO, Paris, p 77-80

Duarte CM, Terrados J, Agawin NSR, Fortes MD, Bach S, Kenworthy WJ (1997) Response of a mixed Philippine seagrass meadow to experimental burial. Mar Ecol Prog Ser 147:285-294

Fonseca MS (1996) The role of seagrasses in nearshore sedimentary processes: a review. In: Roman C, Nordstrom K (eds) Estuarine shores: hydrological, geomorphological and ecological interactions. Blackwell Scientific Publications, Boston, p 261-268

Fonseca MS, Bell SS (1998) Influence of physical setting on seagrass landscapes near Beaufort, North Carolina, USA. Mar Ecol Prog Ser 171:109-121

Fonseca MS, Zieman JC, Thayer GW, Fisher JS (1983) The role of current velocity in structuring seagrass meadows. Estuar Coast Shelf Sci 17:367-380 
Gallegos M, Merino M, Marbà N, Duarte CM (1993) Biomass and dynamics of Thalassia testudinum in the Mexican Caribbean: elucidating rhizome growth. Mar Ecol Prog Ser 95:185-192

Goodman JL, Moore KA, Dennison WC (1995) Photosynthetic responses of eelgrass (Zostera marina L.) to light and sediment sulfide in a shallow barrier island lagoon. Aquat Bot 50:37-47

Kenworthy WJ, Zieman JC, Thayer GW (1982) Evidence of the influence of seagrass on the benthic nitrogen cycle in a coastal plain estuary near Beaufort, North Carolina (USA). Oecologia 54:152-158

Marbà N, Duarte CM (1994) Growth response of the seagrass Cymodocea nodosa to experimental burial and erosion. Mar Ecol Prog Ser 107:307-311

McRoy CP, Helfferich C (1980) Applied aspects of seagrasses. In: Phillips RC, McRoy CP (eds) Handbook of seagrass biology. Garland STPM Press, New York, p 297-344

Murphey PE, Fonseca MS (1995) Role of high and low energy seagrass beds as nursery areas for Penaeus duorarum in North Carolina. Mar Ecol Prog Ser 121:91-98

Preen AR, Long WJL, Coles RG (1995) Flood and cyclone related loss, and partial recovery, of more than $1000 \mathrm{~km}^{2}$ of seagrass in Hervey Bay, Queensland, Australia. Aquat Bot 52:3-17

SAS (1986) SAS system for linear models. SAS Institute, Cary, $\mathrm{NC}$

Editorial responsibility: Kenneth Heck (Contributing Editor), Dauphin Island, Alabama, USA
Shepherd SA, McComb AJ, Bulthuis DA, Neverauskas V, Steffensen DA, West R (1989) Decline of seagrasses. In: Larkum AWD, McComb AJ, Shepherd SA (eds) Biology of seagrasses. Elsevier, Amsterdam, p 346-393

Suchanek TH (1983) Control of seagrass communities and sediment distribution by Callianassa (Crustacea, Thalassinidea) bioturbation. J Mar Res 41:281-298

Terrados J, Duarte CM, Fortes MD, Borum J and 7 others (1998) Changes in community structure and biomass of seagrass communities along gradients of siltation in SE Asia. Estuar Coast Shelf Sci 46:757-768

Thayer GW, Kenworthy WJ, Fonseca MS (1984) The ecology of eelgrass meadows of the Atlantic coast: a community profile. US Fish and Wildlife Service, FWS/OBS-84/02, Washington, DC

Vermaat JE, Agawin NSR, Fortes MD, Uri JS, Duarte CM, Marbà N, Enríquez S, van Vierssen W (1996) The capacity of seagrasses to survive increased turbidity and siltation: the significance of growth form and light use. Ambio 25(2): 499-504

Ziebis W, Forster S, Huettel M, Jorgensen BB (1996) Complex burrows of the mud shrimp Callianassa truncata and their geochemical impact in the seabed. Nature 382: $619-622$

Zieman JC (1974) Methods for the study of the growth and production of turtle grass, Thalassia testudinum König. Aquaculture 4:139-143

Submitted: January 30, 2001; Accepted: March 14, 2003 Proofs received from author(s): May 28, 2003 